exposure to alkylating agents of different origin, from dietary to occupational, to medicinal. Details on all the currently available techniques for the detection of DNA adducts are given, and it is interesting and encouraging to see that, since the last meeting in 1983, progress has been made in the application of such techniques to the measurement of DNA damage in human populations, as reported by several authors.

Limited space, however, is devoted to epidemiological studies and only a few chapters discuss the link between DNA adduct detection and risk assessment. Furthermore, the absence of reports on strategies of cancer prevention was most disappointing. It would have been of great interest, as anticipated in the title, to learn how the existing techniques could be applied to the prevention of some environmental cancers.

Despite these shortcomings, the book offers comprehensive and updated information on the latest achievements in molecular dosimetry studies and provides some useful reading to scientists involved in this field of research.

ANNA MARIA BEDFORD

Tumor Progression and Metastasis. UCLA Symposia on Molecular and Cellular Biology. New Series. Vol. 78. Ed GL Nicolson, IJ Fidler. (Pp 322; \$140.00.) Alan R Liss Inc. 1988. ISBN 0-8451-2677-6.

Altered Glycosylation in Tumor Cells. UCLA Symposia on Molecular and Cellular Biology. New Series. Vol. 79. Ed CL Reading, S Hakomori, DM Marcus. (Pp 350; $\$ 140 \cdot 00$.) Alan R Liss Inc. 1988. ISBN 08451- 2678-4.

These books contain papers of varying length and quality that represent the proceedings of UCLA symposia held in Keystone, Colorado in April 1988. Professor Robin Weiss has recently reviewed the proceedings of a UCLA symposium published in the same series ( $J$ Clin Pathol 1988;41:1139-1140) and we echo his doubts over the value of such publications. It is claimed that Volume 78 "thoroughly reviews the pathogenesis of metastasis and the unique properties of highly malignant cells and their microenvironment" and that Volume 79 "comprehensively explores the underlying regulation of altered glycosyla- tion after oncogenic transformation and the functional significance of these changes". As suggested by Professor Weiss, it is highly likely that the meetings were useful forums for the exchange of new data and views, but the books, although well presented, do not live up to these rather ambitious claims. Some papers in both books describe interesting and well performed studies. But many contain preliminary data or, in some cases, brief reviews of the work of a particular laboratory. In some cases the latter is little more than ex cathedra statement with little reference to the work of other groups.

Of particular concern is the fact that 126 pages $(39.1 \%)$ of Volume 78 and 205 pages (58.6\%) of Volume 79 have been published in the Journal of Cellular Biochemistry (Alan $R$ Liss Inc) in exactly the same format. Indeed, in both volumes these pages are paginated twice, once for the book and once with the journal page numbers. These books each cost \$140, and since, in general, the useful papers were the ones that have previously appeared in the Journal of Cellular Biochemistry, we find it difficult to imagine who would buy them. Perhaps they are purchased by individuals and libraries who are unaware of the double publication. Is it right that such blatant double publication occurs? Perhaps the editors and readers of the J Clin Pathol might like to comment?

STELLA KEEBLE

\section{Some new titles}

The receipt of books is acknowledged, and this listing must be regarded as sufficient return for the courtesy of the sender. Books that appear to be of particular interest will be reviewed as space permits.

Cases in Chemical Pathology. A Diagnostic Approach. 2nd ed. RN Walmsley, LR Watkinson, ESC Koay. (Pp 365; A\$40.00.) The Australian Association of Clinical Biochemists. 1988. ISBN 981-3096-05-5.

The Clinical Chemistry of Laboratory Animals. Eds WF Loeb, FW Quimby. (Pp 519; £38.50.) Pergamon Press. 1988. ISBN 0080351808 .

Vertebral Malformations. K Theiler. Advances in Anatomy Embryology and Cell Biology. (Pp 99; 145 figs.; soft cover DM 98.00.) Springer. 1989. ISBN 3-540-19359-6.

\title{
Corrections
}

Dr JW Keyser's authorship was omitte from the book Human Plasma Proteins, a review of which was published in thi Journal.

In the summary of the paper, Diagnosis of progress in multifocal leucoencephalopath by hybridisation techniques, the studies material from the second patient was incorrectly stated as being from a necropsy specimen: it was, in fact, obtained from $P$ brain biopsy specimen. ( $J$ Clin PathoL 1989;42:153-61.)

Authorship of the paper, Lupus anticoagulant, anticardiolipin antibodie and human immunodeficiency virus ino haemophilia was wrongly attributed to Gijo Savage; it should have been attributed to GS Savidge. (J Clin Pathol 1989;42:629-33.) 